\title{
Vesicoureteric reflux and renal scars in asymptomatic siblings of children with reflux
}

\author{
Rajko B Kenda, Jurij J Fettich
}

\begin{abstract}
The purpose of the study was to determine the incidence of vesicoureteric reflux (VUR), renal scars and hypertension in asymptomatic siblings of children with VUR. The study comprised 105 siblings of patients with VUR. Their age ranged from 4 months to 6.3 years. All had a direct radionuclide voiding cystography (DRVC) performed, and VUR was detected in 47 of 105 (45\%). High grade VUR in the first year of life had an incidence of $\mathbf{5 0 \%}$ compared with a $9 \%$ incidence in siblings older than 2 years, while only one of the 27 siblings with a low VUR grade was younger than 1 year. In 43 of 47 siblings with VUR, a technetium-99m dimercaptosuccinic acid ( ${ }^{99 m}$ Tc-DMSA) scan was performed and renal scars were found in 10 , which presents $23 \%$ of siblings with VUR who were scanned and $10 \%$ of all siblings studied. One child had hypertension. Identifying VUR among asymptomatic siblings could possibly prevent renal damage and its consequences. Thus, the predictive value of positive family history alone in identifying VUR was $45 \%$ while $23 \%$ of siblings had renal scars. This incidence justifies the routine investigation of asymptomatic siblings, by using DRVC at an early stage.
\end{abstract}

Vesicoureteric reflux (VUR) is the most common abnormality detected in children with urinary tract infection (UTI). According to different authors, it is present in $22 \%$ to $52 \%$ of the children studied. ${ }^{1-5}$ On the other hand, the incidence has been estimated to be $1 \%$ to $2 \%$ in the general population. ${ }^{6}$ The rationale of detecting VUR is that by close follow up and/or either surgical or conservative treatment, the risk of renal damage (scarring) and its consequences due to the VUR itself, or to the VUR with associated UTI may be minimised.

The incidence of VUR among siblings (even asymptomatic) of children with known VUR is as high as $45 \% .^{7-11}$ However, it was not until direct radionuclide voiding cystography (DRVC) with its low radiation exposure was routinely used that VUR detection in siblings became a more widely accepted procedure. Because VUR is normally detected after the UTI, little is known about the natural history of sterile VUR in children and there has not been sufficient data regarding their renal status (scars, hypertension) to recommend screening for VUR routinely. It is known from experimental studies in animals that high pressure reflux can produce renal damage. ${ }^{12-13}$

The purpose of this study was to determine the incidence of VUR in asymptomatic siblings under the age of 6 of patients with VUR and to determine the incidence of renal scars and hypertension in asymptomatic siblings with proved VUR. The results might justify a recommendation to look for VUR in young siblings.

\section{Patients and methods}

One hundred and five siblings of patients with known VUR were admitted to the study from July 1987 to June 1991 inclusive. In 90 families one sibling was evaluated. Two siblings were studied in six families and three in one family. There were $56(53 \%)$ boys and $49(47 \%)$ girls. The age of the siblings ranged from 4 months to 6.3 years (mean age 3.3 years). Fourteen $(13 \%)$ children were younger than 1 year, $24(23 \%)$ were between 1 and 2 years, while $67(64 \%)$ were older than 2 years. They all had a negative history of UTI and, at the time of admission, they were all free of symptoms.

All children had a DRVC performed and VUR was found in 47 (only a 4 month old boy had a $x$ ray voiding cystogram instead of DRVC). Of 47 children with VUR, 43 also had technetium-99m dimercaptosuccinic acid ( ${ }^{99 \mathrm{~m}}$ Tc-DMSA) scintigraphy done (in four patients with VUR grade 1 parental permission for DMSA scintigraphy could not be obtained).

The results were reviewed by two independent observers. In cases where there was disagreement, a consensus was reached.

For statistical analyses the $\chi^{2}$, Student's $t$ test, Jonckheere-Terpstra test, and linear by linear association test (StatXact software by Cytel Software Company) were used.

\section{TECHNIQUE OF DIRECT VOIDING RADIONUCLIDE} CYSTOGRAPHY

Children were catheterised under aseptic conditions. ${ }^{99 \mathrm{~m}} \mathrm{Tc}$ as sodium pertechnetate was added to sterile isotonic saline in concentrations of $40-80 \mathrm{MBq} / \mathrm{l}$. The bladder was slowly filled with the radiotracer solution under hydrostatic pressure $\left(40-60 \mathrm{~cm} \quad \mathrm{H}_{2} \mathrm{O}\right)$. When bladder capacity was reached, or when the child showed the urge to void, the catheter was removed, and the voiding usually began within a short period of time. Since 1990 a cyclic DRVC (filling the bladder and having the infant void around the catheter two or three times) has been used instead of conventional DRVC to increase the accuracy of the procedure. A computerised gamma camera (General Electric Maxi Camera 300, computer Digital PDP 11/34) was used to 
allow simultaneous visualisation of the radiotracer and to record data at a rate of 1 frame/5 seconds. Data were reviewed with image enhancement by decreasing the upper threshold to $20-30 \%$ of maximal radioactivity in the bladder.

All children received co-trimoxazole (Bactrim) $6 \mathrm{mg} / \mathrm{kg}$ divided into two doses for three days to prevent UTI after catheterisation.

VUR was classified as unilateral or bilateral. According to its extent it was graded as: VUR 1, radiotracer reaching the ureter only; VUR 2, radiotracer reaching the pelvis; and VUR 3, radiotracer reaching the pelvis, which seemed dilated.

\section{TECHNIQUE OF ${ }^{99}$ Tc-DMSA SCINTIGRAPHY}

DMSA scintigraphy was performed two hours after the injection of ${ }^{99 \mathrm{~m}}$ Tc-DMSA. The dose was adjusted for the child's height and weight. One posterior and two posterior oblique images containing 300000 counts each were obtained with a gamma camera (Siemens Basicam ZLC Digitrac 75) and a low energy all purpose collimator, using an appropriate zoom. The relative contribution of each kidney to the global renal function was calculated using a computer image in posterior projection. DMSA scans were considered to be abnormal if there were focal or generalised scars, or if unilateral function was less than $45 \%$ of total glomerular filtration.

\section{Results}

Comparing index children and siblings, no significant difference was found in terms of sex ratio $(p=0 \cdot 4)$, nor was such a difference found between the sex of index children and VUR grade of siblings $(p=0 \cdot 4)$. There was no significant association between VUR grades of index children and VUR grades of siblings when compared as a whole group $(p=0.5)$. However, in siblings under 1 year of age, the JonckheereTerpstra test and linear by linear association test showed significant $(p=0.04)$ positive relationship between VUR grades of index children and VUR grades of siblings, implying that index children with higher grade VUR also had siblings with higher grade VUR. We found that where index children had VUR grade 2 or 3 , six of eight siblings under 1 year of age, also had VUR grade 2 or 3 .

VUR was detected in $47(45 \%)$ of 105 siblings. It was bilateral in 25 and unilateral in 22 of the patients, thus making 72 refluxing units. The grades of VUR were distributed as follows: 42 (58\%) were grade 1, $24(33 \%)$ were grade 2 , and six ( $8 \%$ ) VUR were grade 3 . There was no significant difference between groups of siblings without VUR and those with VUR grade 1,2 , or 3 in terms of sex ratio $(p=0.7)$, but a significant difference $(p=0.0001)$ was found in terms of age (table). The mean age of the children with VUR grade 2 and 3 was 24 months, compared with the mean age of 49 months in those children with grade 1 VUR, and 39 months in children without VUR. High grade VUR (grade 2 and 3) had an incidence of $50 \%(7 / 14)$ in the first year of age, compared
Distribution of VUR grades 1 to 3 according to age of 47 children with VUR among 105 asymptomatic siblings (in cases of bilateral VUR of different grades, the higher grade was considered). Figures are cases and percentage within each age group

\begin{tabular}{lcccc}
\hline $\begin{array}{l}\text { Age } \\
\text { (months) }\end{array}$ & \multicolumn{4}{l}{ VUR grade } \\
\cline { 2 - 5 } & 0 & $l$ & $2 / 3$ & Total \\
\hline $0-12$ & $6(43)$ & $1(7)$ & $7(50)$ & $14(100)$ \\
$13-24$ & $12(50)$ & $5(21)$ & $7(29)$ & $24(100)$ \\
$25-76$ & $40(60)$ & $21(31)$ & $6(9)$ & $67(100)$ \\
Total & $58(55)$ & $27(26)$ & $20(19)$ & $105(100)$ \\
\hline
\end{tabular}

with a $9 \%(6 / 67)$ incidence in siblings older than 2 years. On the other hand, only one of the 27 siblings with VUR grade 1 was younger than 1 year.

In 43 of 47 siblings with proved VUR, ${ }^{99} \mathrm{~m}$ TcDMSA was performed and focal defects suggestive of renal scarring were found in 10 cases, which presents $23 \%$ of siblings with VUR who were scanned and $10 \%$ of all siblings in the study. However, in all cases unilateral renal function was more than $44 \%$ of total glomerular filtration. Comparing siblings with VUR and renal scars and those with VUR without scars, no significant difference between the two groups was found in terms of age $(p=0 \cdot 2)$ and grade of VUR $(p=0.6)$. Significant difference $(p=0.02)$ was noted in terms of sex ratio. Nine siblings with scars were girls and only one was a boy.

In one 9 month old male sibling, in addition to the right VUR, grade 2, a left side kidney agenesis was also discovered. Raised blood pressure was found in one 32 month old boy with bilateral VUR, grade 2, and scars in the upper left pole.

\section{Discussion}

The study indicated that the incidence of VUR in general, and of VUR grades 2 and 3 in particular, was much higher in siblings younger than 1 year, than in older siblings, which correlates with the well known fact that VUR tends to disappear with age.

The rationale of detecting VUR in siblings lies in the fact that children with VUR are more prone to pyelonephritis and to develop renal scars than do children without VUR. Besides, it is of considerable interest that most reflux associated renal scars are already present when the patient is first investigated. This suggests that the development of irreversible renal scarring within one week after the introduction of Escherichia coli into the bladder of refluxing piglets, as shown by Ransley and Risdon, ${ }^{14}$ may also be true in humans. It also indicates the need for more prompt diagnosis and vigorous treatment of the first UTI, as already suggested by many authors. ${ }^{15-17}$ It has been widely accepted that renal scarring tends to develop mainly in infants and young children, and that new scars or progression of previous scars rarely occur after the age of 5 years. Recently there is growing evidence that this may not be so, and that the severity of VUR, the frequency of UTI and abnormal bladder function are the main contributing factors. ${ }^{18}$ It might be hoped that 
close follow up and/or either surgical or conservative treatment might reduce the risk of renal scarring in asymptomatic siblings found on the basis of family history to have VUR as most of them will not yet have suffered a symptomatic UTI. However promising, this presumption has not yet been proved.

DRVC is a highly sensitive method and exposes the patient to much less radiation than the $x$ ray voiding cystography. ${ }^{11} 19$ We believe that the benefit of DRVC in detecting VUR in asymptomatic siblings outweighs the invasiveness of the procedure. We also believe that if screening is to be recommended, DRVC should be the procedure of the first choice. It is the VUR we are looking for, and ultrasound, intravenous urography, or DMSA scintigraphy could only identify children, to whom damageat least to a certain extent-has already been done. Ten per cent of siblings in this study were found to have renal scars. They do not seem to be of any clinical significance yet, except in one of the 10 children with renal scarring, who has already been shown to have hypertension. Before a more conclusive decision is reached regarding the rationale of screening asymptomatic siblings of patients with VUR, a long term follow up should be done to watch the progress of scars and the development of hypertension in this group and compare it with the findings in children found to have VUR after bacteriologically proved UTI.

It is not clear up to what age the asymptomatic siblings of index children with VUR should be investigated. Van den Abbeele et al recommend 10 years as the limit, beyond which siblings should be screened with DRVC, while with older siblings ultrasonography of the kidneys should be done. ${ }^{10}$ Noe and Jerkins studied 287 siblings of 221 index patients with VUR and found a $32 \%$ incidence of reflux in siblings. However, siblings younger than 18 months had a much higher incidence of reflux than did the older siblings. They recommend a screening voiding cystogram, preferably with radionuclide, for siblings younger than 5 years of age. ${ }^{20}$ Their data correlate with ours, where the highest incidence of high grade VUR was seen in children under 2 years of age. On the other hand, a certain number of refluxes of grade 1 (which in our study were discovered mostly in the older children), would have probably been of higher grade if the siblings had been investigated at an earlier age. Aggarwal and Verrier Jones report 33 asymptomatic children with a family history of reflux nephropathy or VUR in first degree relatives. ${ }^{21}$ Fifteen (45\%) showed some abnormality of the renal tract on ultrasound or micturating cystourethrography, or both, and 12 of them were under 2 years of age.

Based upon present data we believe that the age limit of siblings to whom the DRVC should be done could be lower than 10 years of age as recommended by Van den Abbeele et al, ${ }^{10}$ but not lower than 2 years. Currently it is our practice to screen with DRVC all preschool siblings of the index child, while older siblings have renal ultrasonography. In addition, parents of a child with VUR are instructed that a newborn sibling should be screened as soon as possible. This procedure is also likely to be justified for children of parents with reflux nephropathy.

In conclusion, identifying children with VUR among asymptomatic siblings could possibly prevent renal damage and its consequences. The predictive value of positive family history alone in identifying VUR in our study was $45 \%$, and $23 \%$ of siblings with VUR were found to have renal scars. This appears high enough to justify the routine investigation of asymptomatic siblings of children with VUR, by using DRVC at an early age.

We wish to thank Janez Stare MSc for help with statistical analysis and Linda Cimperman for assistance in the preparation of the manuscript; Tone Zakelj and Ignac Zidar provided technical assistance. The study was financially supported by the Ministry for Research and Technology (grant: URP: C3-0561363).

1 Alon U, Pery M, Davidai G, Berant $M$. Ultrasonography in the radiologic evaluation of children with urinary tract infection. Pediatrics 1986;78:58-64.

2 Blickman JG, Taylor GA Lebowitz RL. Voiding cystourethrography: the initial radiologic study in children with urinary tract infection. Radiology 1985;156:659-62.

3 Kenda R, Kenig T, Silc M, Zupančič Ż. Renal ultrasound and excretory urography in infants and young children with urinary tract infection. Pediatr Radiol 1989;19:299-301.

4 Leonidas JC, McCauley RGK, Klauber GC, Fretzayas AM. Sonography as a substitute for excretory urography in

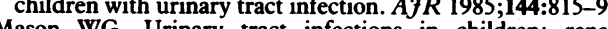
Mason WG. Urinary tract infections in children:
ultrasound evaluation. Radiology 1984;153:109-11.

6 Burger RH, Smith C. Hereditary and f ?milial vesicoureteral reflux. F Urol 1971;106:845-51.

7 Jerkins GR, Noe HN. Familial vesicoureteral reflux: a prospective study. $\mathcal{F}$ Urol 1982;128:774-8.

8 Kenda RB, Kenig T, Budihna N. Detecting vesico-ureteral reflux in asymptomatic siblings of children with reflux by direct radionuclide cystography. Eur $\mathcal{F}$ Pediatr 1991;150: 735-7.

9 Noe HN. The relationship of sibling reflux to index patient dysfunctional voiding. $\mathcal{J}$ Urol 1988;140:119-20.

10 Van den Abbeele AD, Treves ST, Lebowitz RL, et al. Vesicoureteral reflux in asymptomatic siblings of patients with known reflux: radionuclide cystography. Pediatrics 1987;79:147-53.

11 Willi U, Treves S. Radionuclide voiding cystography. Urol Radiol 1983;5:161-73.

12 Hodson CJ, Maling TMJ, McManamon BJ, et al. The pathogenesis of reflux nephropathy: chronic atrophic pathogenesis of reflux nephropathy: chronic atr
pyelonephritis. $B r \mathcal{F}$ Radiol $1975 ; 48$ suppl 13:1-26.

13 Roberts JA, Kaack MB, Morvant AB. Vesicoureteral reflux in the primate. IV Infection as a cause of prolonged highin the primate. IV Infection as a cause

14 Ransley PG, Risdon RA. Reflux nephropathy: effects of antimicrobial therapy on the evolution of the early pyelonephritic scar. Kidney Int 1981;20:733-42.

15 White RHR. Management of urisary tract infection and vesicoureteric reflux in children. $B M F$ 1990;300:1391-4.

16 Winberg J, Bollgren I, Kallenius G, Mollby R, Svenson SB Clinical pyelonephritis and focal scarring. Pediatr Clin North Am 1982;29:801-14.

17 Winter AL, Hardy BE, Alton DJ, Arbus GS, Churchill BM. Acquired renal scars in children. $\mathcal{f}$ Urol 1983;129:1190-4.

18 Shimada K, Matsui T, Ogino T, Ikoma F. New developmen and progression of renal scarring in children with primary VUR. Int Urol Nephrol 1989;12:153-8.

19 Fernbach SK, Conway JJ. The evolving uroradiographic evaluation of the lower urinary tract in neonates with myelomeningocele. Urol Radiol 1987;9:141-5.

20 Glassberg KI. Annual meeting of the section of pediatric urology. Pediatrics 1988:81:588-94.

21 Aggarwal VK, Verrier Jones K. Vesicoureteric reflux: screening of first degree relatives. Arch Dis Child 1989;64: 1538-41. 